\title{
LA REINSERCION DE LA MUJER EX-COMBATIENTE. UN LEGADO DE GUERRA
}

\author{
Irene Romero*
}

"Yo extraño la guerra. Era una sensación especial la que vivíamos entonces, pero si puedo voy a dedicarme a estudiar para maestra.... "Para mi la reinserción pasa por reencontrarme con mi familia y cumplir con mi nueva tarea política...." "Yo lo que más quisiera es volver a ver a mis hijos..."

Las frases anteriores corresponden a tres mujeres que poco tienen en común, con excepción de su condición de ex-guerrilleras.

Con el final de la guerra los fusiles callaron, y con su silencio quedó atrás toda esa extraña realidad que inundó sus vidas; ahora es necesario buscarle un nuevo sentido práctico, un sentido que facilite su reinserción a la vida civil.

Este proceso no es más que el retorno a la vida institucional o de legalidad jurídica de los ex-combatientes del guerrillero FMLN (Frente Farabundo Martí para la Liberación Nacional) y del ejército salvadoreño que posibilite su funcionalidad social.

Esta nueva dinámica hace que El Salvador se encuentre en la actualidad viviendo una de las etapas más importantes en su reciente historia.

A partir de 1980 la Fuerza Armada salvadoreña y la guerrilla del FMLN se enfrentaron en una lucha armada durante más de 10

\footnotetext{
- Profesora del Departamento de Sociología y Ciencias Políticas.
} 
años ocasionando más de 80 mil muertos, alrededor de 7 mil desaparecidos y graves violaciones a los derechos humanos, sin que ninguno de los ejércitos se impusiera militarmente sobre el otro.

Este impasse así como las presiones internacionales obligaron a que el gobiemo de Alfredo Cristiani y la Comandancia General del FMLN se sentaran a la mesa de negociaciones.

Cuando ambas delegaciones presentaron las propuestas que posibilitaron el fin de la guerra, se enfrentaron a una realidad que impuso la búsqueda de mecanismos no solo de soluciones políticas a un problema militar, sino que debían lograr prontas soluciones a la grave problemática socio-económica que el fin del conflicto traería.

Con el logro de los Acuerdos de Paz en 1992 firmados por el gobiemo y el FMLN no solo acordaron concentrar a sus respectivos ejércitos, reformar el sistema judicial, la puesta en marcha de un plan de reconstrucción nacional, sino también el cumplimiento de programas concretos para reintegrar en nuevos espacios políticos, económicos y sociales a aquellos que una vez empuñaron las armas, como uno de los retos mas importantes que el silencio de los fusiles impone.

\section{Negociando la reinserción}

"Las negociaciones fueron realmente duras, ya que debíamos entrar al período de debate político en donde no podíamos perder las perspectivas de la lucha misma", explica Nidia Díaz la ex-comandante guerrillera que ahora desarrolla una lucha parlamentaria contra sus antiguos enemigos.

Ese debate obligó a la búsqueda de alternativas sobre el tipo de programas para la reconversión de los ex-combatientes de ambos bandos, recuerda Nidia, pues a pesar que los Acuerdos establecen toda una serie de mecanismos que permitan el logro de soluciones políticas para algunos problemas que originaron la guerra, no planteó soluciones específicas a la problemática de la reinserción de los ex-combatientes a partir de la perspectiva de los géneros.

Es decir que los programas se consideraron en términos unilaterales, a partir de las necesidades para los guerreros, sin percatarse de la especificidad que la participación de las mujeres al interior del FMLN imprimiría al retorno a la vida civil. 
Según los Acuerdos la reinserción contemplará básicamente la incorporación a la vida civil a partir de cuatro programas : inserción económica, programas de educación, programas de vivienda y de salud.

Si bien estos programas no plantean problemas para los ex-combatientes del ejército salvadoreño compuesto por mas de 60 mil efectivos en su mayoría hombres, el ejército guerrillero si los tiene debido a su composición, ya que de sus mas de 13,600 combatientes alrededor del $30 \%$ son mujeres para quienes no hubo un diseño especifico en los programas de reconversión.Es decir que para muchas mujeres miembros del FMLN las alternativas de los proyectos de reinserción se quedan cortos frente a sus expectativas.

Debido a la complejidad de las instancias que la reconversión contempla, pues en términos formales significa un mayor nivel de democratización, los acuerdos establecieron que era necesario pasar por una desmilitarización de la sociedad (que implicaba la depuración y reducción del ejército), la realización de reformas al sistema judicial que garanticen una mejor administración de justicia, así como la participación en los espacios políticos por parte del FMLN.

Solamente con el cumplimiento de estos aspectos se posibilitaría el desarrollo de los programas de reinserción, principalmente en un país tradicionalmente agrícola como El Salvador, cuya economía basada en la exportación de productos tradicionales ha provocado una elevada concentración del poder económico y político en manos de un sector minoritario con capacidad de controlar la administración de justicia.Sin modificaciones a nivel jurídico el marco para la reinserción no podría establecerse, ya que el tema de las tierras por ejemplo toca uno de los aspectos medulares que dieron origen al conflicto armado.

"Cuando entramos a la negociación esperamos salir victoriosos, es decir que lo que habíamos acumulado de poder a nivel económico, político, social, todos estos años no se nos fuera a revertir, sino que se transformara, se institucionalizara", explica Nidia Díaz.

Según la ex-rebelde, en la mesa de negociación se discutió la incorporación a la vida civil tratando de que no desacumulara lo 
que la lucha armada había logrado durante la guerra, sino que se buscaba transformarla. Dicha transformación se refiere a una vuelta a la institucionalidad y a la reinserción económica-productiva de los ex-combatientes a través de la obtención de créditos y tierra para actividades productivas e industriales, capacitación empresarial para microempresarios, y la participación en la Policía Nacional Civil y las instituciones del Estado, como parte de la lucha en la instancia política.

\section{La mujer en el Frente}

_l FMLN (actualmente convertido en partido político) accionó $\mathcal{L}$ durante mas de 10 años como una fuerza político-militar que se origina durante los años 80 , a partir de la lucha organizativa de varios grupos de oposición a los gobiernos tradicionalmente militares de El Salvador; dicha oposición estuvo conformada por varios gremios de trabajadores, algunos intelectuales, estudiantes, amas de casa, campesinos, que no encontraron en los canales institucionales los medios adecuados para la solución de sus demandas.

A medida que la organización opositora crecía lo mismo ocurrió con la represión estatal, que los llevo a dar el salto cualitativo-estratégico para su conformación como fuerza militar con capacidad de lucha y desestabilización política.

Dada la diversidad de su conformación y del carácter civil de la lucha, las mujeres no se quedaron de lado y tomaron muchas de ellas la opción armada, haciendo que la fuerza guerrillera de casi 8 mil combatientes (en aquellos años), fuera conformada en un $30 \%$ por mujeres que realizaron gran diversidad de tareas requeridas por la co-existencia de una estructura política o cuadros no militares (radistas, brigadistas, correos, cocineras,etc), así como de una estructura militar, es decir las combatientes.

María Delia Cornejo o "Ana", es una ex-radista de 35 años que ingreso a las filas del FMLN a los 14 después de trabajar en labores pastorales con el padre Rutilio Grande, que fue asesinado por un cuerpo de seguridad, y que en la actualidad se desempeña como capacitadora de mujeres en un organismo feminista; María Marta Valladares o "Nidia Díaz" es a sus 41 años una de las más 
legendarias figuras guerrilleras y que ahora aspira a ser miembro del congreso en la próxima contienda electoral, y Marisol Salgado o "Chanita" es a sus 20 años la única guardaespaldas mujer encargada de darle seguridad a un importante miembro del Partido Comunista.

Esta tres mujeres tienen en común su lucha guerrillera, pero sus procesos de reinserción están siendo totalmente diferentes debido no solo a la diferencia de edades y de niveles educativos conque cuentan, sino también al desarrollo de diferentes tareas políticas y/o militares es decir experiencias muy particulares para cada una de ellas.

Sus historias sobre su reinserción servirán para ilustrar casos particulares, talvéz atípicos, pero que reflejan en buena medida la realidad de la diferenciación que las mujeres enfrentan al regresar a la vida ordinaria.

\section{Marginación vrs. integración}
Cuando se firmaron los Acuerdos de Paz no se tomó en cuenta que en la sociedad salvadoreña la mujer sufre una discrimi- nación de carácter estructural que al no explicitarse su modifica- ción a nivel jurídico tiende a verse reforzada.

El problema es que frente a la dualidad de la composición de las estructuras del FMLN debió quedar especificado que los programas de reinserción consideraban tanto al $12 \%$ de las mujeres de la estructura política, al $77.5 \%$ de las mujeres de la estructura militar, así como al $10.3 \%$ de lisiadas; debido a esa falta de especificidad ahora únicamente las mujeres ex-combatientes o aquellas que se verificaron (esto último adquiere cada vez más importancia) son sujetas de ser beneficiadas por los programas.

El proceso de reinserción de las ex-combatientes parte de la verificación que la ONUSAL (misión de Observadores de Naciones Unidas para El Salvador) realizo en los puntos de concentración del FMLN; este consistía en ubicar a los hombres y mujeres combatientes en 15 lugares para darles cierta nivelación académica y posteriormente desmovilizarlos para incorporarlos en los programas de reinserción por pequeños grupos. A través de este proceso dejaron sus armas para volver a la vida civil, es decir dejaron 
de ser formalmente combatientes guerrilleras.

Resulta importante aclarar que la fase de concentración se diseñó exclusivamente para los cuadros combatientes del FMLN, sin considerar a los cuadros políticos que desarrollaron tareas no-militares, quedando éstos sin los beneficios de la fase de desmovilización.

Según ONUSAL en la actualidad existen 3285 mujeres desmovilizadas que se encuentran listas para reintegrarse a la vida civil, cuyas edades oscilan entre los 15 y los 29 años, es decir forman parte de la PEA (Población Económicamente Activa) del país; a pesar de esa disposición de las ex-guerrilleras para volver a la vida civil y los acuerdos firmados sus posibilidades reales se ven limitadas en tanto solamente pueden tener acceso una minoría de ellas, mientras la mayoría deberá regresar a aquellas actividades tradicionales de la mujer, debido principalmente a la deficiencia misma con que la reinserción fue establecida en el momento de la negociación.

Para Nidia Díaz la ex-comandante rebelde que participó en las discusiones, no se trata de una deficiencia, sino de una realidad impuesta por las correlaciones de fuerza existentes a ese momento. "La reinserción de las mujeres ex-combatientes no se planteó de manera específica sino dentro de la globalidad, pues no existía una correlación y espacio para negociar la especificidad". Según la ex-guerrillera, lo que más importaba en la negociación "era la lucha por la vigencia plena de los derechos humanos y el inicio de la democratización, y a cambio de esos logros el FMLN pagaría con el desmontaje de su aparato militar y la incorporación a la vida civil y política de sus combatientes, hombres y mujeres".

Si bien la negociación garantizó ese proceso para hombres y mujeres, el dilema es que las mujeres continúan estando marginadas debido tanto a patrones estrictamente culturales como a problemas de operatividad obligando a que la mayoría vuelva a sus tareas domésticas sin encontrar solución a su creciente frustración.

\section{¿Los fusiles a cambio de qué?}

\footnotetext{
Con la paz el gobierno se comprometió a buscar los fondos necesarios para impulsar los programas de reinserción de los $y$ las ex-combatientes.
} 
Lo anterior puede ser referido a la transferencia a aquellas ex-combatientes que optaron por la reinserción rural, de las tierras estatales que no son reserva forestal, así como lograr la compra de la tierra ofrecida en venta por sus propietarios, a impulsar programas especiales de crédito $\mathrm{y}$ asistencia técnica para actividades agropecuarias y de microempresa, así como a otorgarles vivienda.

$\mathrm{Si}$ bien las mujeres integradas en el proceso de reinserción están dispuestas a aceptar el nuevo reto, éste deberá pasar necesariamente por la modificación de las condiciones de marginalidad en que las mujeres han estado tradicionalmente, así como la adecuación de los mismos programas a una perspectiva de género.

Para Julia Soro, una feminista francesa que se encuentra realizando investigaciones sociales en el país, "en este momento resulta válido preguntar si ahora con la reinserción, las mujeres solamente van a pasársela en la casa el resto de sus días llenándose de hijos como tradicionalmente hacen las mujeres de su familia o bien van a luchar para conquistar una verdadera integración participativa a la vida civil, económica y política".

La respuesta a ese interrogante deberá encontrarse en los programas que la Secretaría de Reconstrucción Nacional (SRN) y la Fundación 16 de Enero (F-16) realizan para la incorporación de la mujer ex-combatiente.

Los programas gubernamentales de reinserción que contempla la Secretaría de Reconstrucción no cuentan actualmente con una clasificación por género que le permita facilitar el acceso a las mujeres al proceso, sino únicamente parte de datos globales.

Esta Secretaría desarrolla cuatro programas de reconversión. En el programa de inserción económica desarrollan las áreas de capacitación agropecuaria y otorgamiento de créditos para cultivo; asistencia técnica agropecuaria; capacitación en industria y servicios, y crédito para microempresas. El programa educativo se refiere a las becas para estudios de secundaria, técnicos y universitarios. Cuenta con un programa de atención médica especializada y continúa con su compromiso de cumplir con el programa de viviendas.

“No, si los programas existen, el problema es que el proceso de 
reinserción o está parado o camina a paso de tortuga, debido básicamente a que no existe una voluntad política del gobierno de cumplir con los compromisos y porque además en la actualidad todos los esfuerzos del Frente, que es el encargado de velar por su cumplimiento, están encauzados hacia la campaña electoral. Ese es el problema", asegura Leo Cabrales un ex-líder rebelde miembro de la Resistencia Nacional ( $R N$ ), que se muestra preocupado por el retraso en el cumplimiento del proceso.

Según una encuesta patrocinada recientemente por UNICEF para mujeres desmovilizadas, que pretende el desarrollo de proyectos productivos y sociales con una perspectiva de género que complemente los programas para la reinserción la solución al problema de la marginalidad reforzada en la mujer por el proceso de reinserción atraviesa serias dificultades. "El paso a la vida civil no ha sido fácil ni para el hombre ni para la mujer. Nuestra sociedad es sumamente machista y patriarcal, lo cual significa que la mujer ex-combatiente está bajo presión de cumplir su papel estereotipado, por ejemplo, enfrenta las contradicciones típicas de comprar ropa y maquillaje sin contar con el dinero suficiente, de convertirse en sujeto productivo y al mismo tiempo de cumplir con su papel de ama de casa", explica la encargada del proyecto.

La muestra de la encuesta la conformaron 1100 mujeres que equivalen al $36 \%$ del total de mujeres verificadas en todo el país, de las cuales más de la mitad se localizan en la ciudad capital. De estas el $97 \%$ puede formar parte del sector productivo del país.

Los datos obtenidos señalan entre las principales dificultades que las mujeres desmovilizadas enfrentan :

- Educación, si bien el $87 \%$ desea continuar estudiando, el nivel educativo es muy bajo, lo cual les impide de optar a los programas de becas (únicamente el $4.5 \%$ ha optado por éstas),

- Alrededor del $80 \%$ tienen hijos menores de 12 años bajo su responsabilidad. El $29.3 \%$ son jefas de hogar,por lo cual la búsqueda de los ingresos se vuelve tarea primordial,

- El $71.7 \%$ ha solicitado créditos en el área de microempresas (talleres de costura, pequeños negocios y otros), pero para lograrlos necesitan contar con la respectiva capacitación como 
requisito fundamental,

- Más del $10 \%$ son lisiadas cuyos beneficios han sido nulos o muy reducidos, y solamente el $0.7 \%$ ha pensado en incorporarse a la nueva Policía Nacional Civil ( debido a que para formar parte de ésta se requiere un nivel mínimo de educación que ellas no poseen).

Estas dificultades están provocando que la mayoría tenga que volver a sus tradicionales tareas domésticas, siendo muy pocas las que pueden incorporarse al desarrollo de tareas similares a las que realizaron durante la guerra y mucho menos a posiciones de jefatura al interior de sus partidos, dejando que sea la educación el parámetro casi exclusivo que facilite la reinserción de las mujeres, generando toda una diferenciación social que vuelve más complicado el proceso de democratización buscado por el FMLN.

Según una vocera de la Fundación 16 de Enero, no se trata solamente de los problemas apuntados anteriormente, sino también por que existe "burocratización por parte de la Secretaría de Reconstrucción y la AID (Agencia Internacional para el Desarrollo) en los aspectos administrativos y en el desembolso de los recursos.. así como la falta de voluntad política por parte de las instituciones gubernamentales encargadas de la ejecución.... Pero el problema fundamental ha sido la ejecución de los programas de manera descoordinada, tardía e inoportuna... generando inconformidad e incertidumbre en los ex-combatientes, y talvéz más en las mujeres para quienes no existen ni siquiera un registro específico, lo cual no les puede garantizar la subsistencia de sus familias".

Frente a esta compleja realidad pareciera que el éxito de los programas de reinserción para las ex-combatientes no dependerá únicamente del número de mujeres beneficiadas y de los montos comprometidos a ser otorgados, sino que éste deberá pasar necesariamente por una real y efectiva implementación de los programas, con el fin de posibilitar aquellas transformaciones estructurales de la sociedad que permita el surgimiento de una mujer nueva constructora de su destino. 


\section{Casos de la vida}

\section{Buscando un sentido práctico a la reinserción}

A pesar que de manera formal existen todos los programas con la F-16 no se han cumplido, existen otras instancias que están posibilitando la reinserción de las mujeres.

$Y$ es que para la ex-combatiente la guerra significó la oportunidad de nuevas experiencias, de probar su capacidad misma en situaciones extremas, pero también le permitió guardar el deseo por la vida y el amor por los suyos como parte fundamental de sus vidas.

Esa dinámica está permitiendo que muchas superen el dolor que la pérdida de sus familiares ha significado, o la impotencia que la poca educación provoca, así como enfrentar los retos que la construcción de una nueva sociedad exige.

\section{"Lo que más quisiera ahora es volver a ver a mis hijos"}

M aría Delia o "Ana", es como muchas mujeres campesinas una ex-combatiente que ingresó a las filas del FMLN golpeada por la represión de los cuerpos de seguridad en el campo.

"Yo trabajaba con el padre Rutilio Grande cuando lo mataron. Eso me afectó mucho y me sentí amenazada por lo que decidí incorporarme con las FPL (Fuerzas Populares de Liberación) y venirme a la ciudad en donde me asignaron primero la tarea de brindar cobertura a una casa de seguridad del Partido, pero después pase al campo de batalla", recuerda María Delia quien ahora a sus 35 años y muchas pérdidas en la vida trabaja como capacitadora de mujeres en un organismo feminista.

"A mi como a muchas otras mujeres me golpeo duro la guerra, porque perdí a mi compañero y a mis hijos. El también era guerrillero y jefe de una unidad y lo mataron en un operativo, Yo creí volverme loca, pero lo peor vino después cuando a los dos niños que teníamos se los llevaron a los Estados Unidos unos familiares de él que los habían tenido mientras estábamos en el frente. Parece que creyeron que yo también había muerto y les cambiaron los 
papeles de identificación y se los llevaron hace como cinco años. Nunca los he vuelto a ver", explica Delia mientras las lágrimas comienzan a brotar al recordar a sus hijos perdidos.

Esta mujer que se desempeñó como radista durante toda la guerra se enfrenta ahora no sólo a su soledad por la pérdida de sus hijos sino también a la incertidumbre de la reinserción.

"Mirá, para mi la reinserción ha sido un momento bien duro porque no se vio claro para las mujeres como yo durante la negociación, porque el objetivo principal era la desmilitarización, haciendo que todo mundo hayamos quedado mero mal en esto", comenta sombría

"Ana", quien por haberse dedicado a tareas no-militares no se le ha asignado dentro de ninguno de los programas de la reinserción.

A pesar de su problemática personal, esta mujer amable y espontánea no ha perdido su solidaridad para con sus semejantes.

"Yo lo que estoy haciendo es capacitarme en la teoría de género para poder capacitar a otras mujeres que se sienten más mal que yo y demostrarles que siempre hay opciones, y que para alcanzarlas debemos prepararnos y luchar juntas", sostiene esta capacitadora.

María Delia no sólo no puede tener acceso a la tierra como una parte de los programas, sino que tampoco puede optar a las becas o la capacitación empresarial debido a que no cuenta con el nivel mínimo de educación que se exige.

"Yo se que será bien difícil, pero voy a trabajar y dar lo mejor de mi misma. Sé que de hambre no me voy a morir, pero lo que más quisiera es recuperar a mis hijos y explicarles que todo lo que su papá y yo hicimos fue por amor a ellos y a nuestro pueblo. Sólo cuando logre explicárselos sentiré que nuestro sacrificio no ha sido en vano", finaliza "Ana" cuando su rostro se ilumina ante la perspectiva de reunirse con sus hijos.

"Para mi la reinserción por el reencuentro con mi familia y el cumplimiento de mis tareas políticas"

\footnotetext{
Gí, eso es lo que para María Marta Valladares o Nidia Díaz re Opresenta la reinserción.
} 
Esta mujer alta, muy femenina y sensible, es a sus 41 años para muchos "el lado humano del FMLN", y es que a donde va despierta la simpatía de la gente.

Nidia Díaz es también la legendaria comandante que se presentó a la primera reunión de diálogo en La Palma, Chalatenango, y que solamente después de 8 años y muchas reuniones pusieron fin a la guerra.

María Marta, mujer de extracción media se incorpora a la lucha guerrillera motivada por la injusticia estructural de el país.

Se organiza al principio en el ERP (Ejército Revolucionario del Pueblo) del cual sale para fundar el PRTC (Partido Revolucionario de los Trabajadores del Campo) del cual es actual líder.

Con su hijo José Alejandro,cuyo padre, un revolucionario guatemalteco que fue desaparecido, ha debido enfrentar el dolor de la separación, la incertidumbre del reencuentro y las alegrías que sólo el reconocerse de nuevo les trae.

"Cuando Alex nació lo amamanté por 6 meses, pero después tuve que dejarlo para cumplir mis tareas; luego se decidió que debía trabajar en lo urbano y así fue como pudimos vivir dos años juntos, hasta que me capturaron en el frente", explica Nidia, quien fuera capturada en combate por tropas élites de la Fuerza Aérea y mantenida en prisión hasta que unidades guerrilleras capturaron a la hija del presidente con cuya liberación pudo ser canjeada.

"Con mi captura, la situación se puso realmente difícil para mi familia, pues la mayoría debió abandonar el país. Llegué a tener 18 familiares en el exilio", sonríe mientras recuerda.

"Actualmente mi mamá está muy enferma y una de mis hermanas quiere regresar, pero Alex y yo tenemos el compromiso de que el termine la primaria en Suecia y luego se puede venir", comenta mientras lee una carta reciente de su hermana. "Para mí es bien difícil, porque claro que quiero verlos, pero no puedo hacer a un lado mis nuevas tareas políticas".

Nidia ha sido ratificada como miembro del Comité Político de su Partido; nombrada presidenta de ASPAD (Asociación Salvadoreña para la Promoción de la Democracia) que tiene bajo su cargo la capacitación de líderes para la nueva campaña electoral y la 
obtención de fondos extranjeros para financiar las elecciones dentro de las cual ella misma participó como candidata a diputada.

"Primero se manejó mi nombre como candidata para la vice-presidencia del país, pero francamente mi intención para la lucha no es la búsqueda de un cargo político que me proyecte de manera individual, y aunque la nominación para diputada me resultó difícil de aceptar creo que debo hacerlo para procurar el beneficio de todos aquellos que creyeron siempre en nuestra lucha", explica esta ex-rebelde a quien la nueva dinámica de lucha política le resulta complicada de manejar.

"No tengo mucho tiempo libre. Me gusta pintar, pero no puedo hacerlo, me gusta bailar y no tengo tiempo para la vida social, con excepción de aquella que implica trabajo político, realmente creo que será un momento difícil pero importante el volver a vivir con mi hijo y mi familia", sostiene mientras conversa en una rara entrevista en la cocina de su casa.

Y es que para Nidia Díaz la vida privada es muy corta ya que su vida pública le requiere casi las 24 horas del día, sobre todo ahora que realiza un trabajo en el congreso.

"Me gusta mucho ir a los cantones de San Vicente (departamento al cual representa como candidata), los recorri muchas veces en la guerra y ahora que regreso la gente me reconoce y se me acercan para conversar; me ofrecen algún refresco y muchas veces me quedo a dormir con ellos", narra mientras saca de su enorme bolso marrón un dibujo que le hiciera un campesino recientemente.

Se trata de un sencillo dibujo que éste hiciera mientras ella exponía su plan de campaña, en donde Nidia aparece vestida como guerrillera, con su fusil, su arnés y mochila a hombros. "Es extrano como me miran algunos, sabés, porque yo estaba vestida como civil, normal y los compas todavía me miran así"; pero no es extraño sobre todo si se conoce toda la leyenda que esta mujer significa para muchos,pues continua representando el mito de la mujer guerrillera.

"Mi vida es un compromiso con esta gente. Les debo mucho, por eso mi reinserción deberá combinar mi retorno a la vida fami- 
liar con el cumplimiento de mis tareas políticas. Para eso estoy comprometida", finaliza esta mujer que enfrenta grandes retos políticos diariamente pero cuyos ojos no logran ocultar la emoción que siente al pensar en el encuentro con su hijo.

\section{"Extraño la guerra, pero si puedo me gustaría ser maestra de niños".}

Al escuchar la frase anterior de una jovencita ex-guerrillera que se encarga de garantizar la vida de un miembro del FMLN, se encuentra la búsqueda de nuevas opciones que el fin de la guerra ha traído para las mujeres ex-combatientes.

Para Miguel Sáenz Varela, un prominente miembro del Partido Comunista y actual diputado, su vida depende de una joven casi adolescente que a pesar de su dulzura es toda una estratega militar.

"Sí, la Chanita me cuida a mí y no la cambiaría ni por diez hombres. Cuando en el Partido dijeron que había una mujer en la seguridad nadie la quería por ser mujer, y yo la traje conmigo al saber de quien se trataba. Con los días vino Schafick Handal a decirme que me daba tres hombres de su seguridad a cambio de ella, pero yo no la cambio", comenta Sáenz cuando se le pregunta por su particular guardaespaldas".

Y es que ver a la "Chanita" o Marisol, cargando su mochila al hombro y ayudando a ese hombre con un bastón resulta en extremo particular. Ella es una joven mujer de 20 años muy dulce, de mirada tímida y sonrisa franca que combatió desde los 14 años en las filas de la FAL (brazo armado del Partido Comunista), en donde primero aprendió a utilizar un M-16, luego un AK-47 y finalmente un RPG-7 o lanzagranadas durante la ofensiva de 1989; su destreza la llevó a ser comandante de escuadra (cargo poco usual para mujeres).

Ahora su reinserción pasa por cuidar la vida de un político y combinar su vida con su "compañero de vida" (también miembro de la seguridad de un ex-comandante), con la continuación de sus estudios para lograr ser maestra de niños.

"A mi me eligieron de allá arriba para ser seguridad del doctor 
Sáenz. Creo que me lo he ganado y estoy dispuesta a ponerme las pilas (hacerlo bien) para cumplir con lo que me han asignado", explica "Chanita".

Luego de la firma de los acuerdos ella fue escogida entre muchos combatientes para dar seguridad a la Comandancia General que regresaba a incorporarse a la lucha política, para después sacarlos del país para entrenarlos en una escuela especializada en seguridad para políticos.

"Fue una buena experiencia, que nos enseñaran todo eso nuevo, como detectar un seguimiento en la ciudad, como proteger a la persona bajo mi cargo, pero también fue bonito ver esas carreteras tan grandes, la comida tan rara y la gente diferente. Yo nunca me imaginé que iba a salir de este país algún día, y lo hice", sonríe "Chanita" mientras recuerda su estadía en Europa.

Con su desmovilización como ex-combatiente ha tenido acceso a una parcela de tierra, que espera que algún día se la entreguen, pero ahora debe cuidar a Sáenz y acostumbrarse a organizar su tiempo con su compañero.

“El también es seguridad y no tenemos mucho tiempo para nosotros, pero procuramos pasarla bien cuando estamos juntos. Compartimos una casa y también los oficios domésticos. Pero lo más importante es que he vuelto a la escuela, estudio noveno grado y quiero estudiar para maestra. Ojalá y pueda hacerlo, porque el doctor me apoya y me insiste en que estudie para que pueda superarme", explica esta joven guerrera cuya experiencia durante la guerra no le ha echado a perder los deseos de buscar nuevas opciones. 